\title{
DEVELOPING A PRELIMINARY MODEL PREDICTING THRIPS MOVEMENT INTO CENTRAL OTAGO NECTARINES
}

\author{
A.J. HAYES ${ }^{1}$, G.F. McLAREN ${ }^{2}$ and J.A. FRASER ${ }^{2}$ \\ ${ }^{1}$ Model Research, P.O. Box 41140, St Luke's, Auckland \\ ${ }^{2}$ HortResearch, Clyde Research Centre, Alexandra R.D.1, Central Otago
}

\begin{abstract}
The New Zealand flower thrips, (Thrips obscuratus Crawford) can damage nectarines, with both adults and larvae feeding on developing fruitlets. As T. obscuratus does not overwinter in Central Otago, it is thought that adults are carried on air currents from Canterbury in spring. We investigated if influxes of thrips as detected by sticky board catches over three seasons could be related to environmental variables. Wind direction in Christchurch and local (Clyde) temperatures were identified as the most important factors affecting thrips movement. A preliminary model was developed to predict influxes over the period of highest damage risk for nectarines.
\end{abstract}

Keywords: New Zealand flower thrips, nectarines, damage, model, wind direction, temperature.

\section{INTRODUCTION}

The New Zealand flower thrips (NZFT) Thrips obscuratus (Crawford) is a native thrips which can cause russetting and colour distortion of nectarine fruits through feeding by adults and larvae. The risk of severe damage is highest during flowering and decreases to a negligible level by shuck fall, approximately 8 weeks later (McLaren 1992). Thrips are highly mobile, flying from tree to tree and moving around within trees during the day, and will move successively from apricots to nectarines to plums and cherries as each crop comes into bloom. However, the timing of thrips influxes on nectarines varies from year to year, and in some years they do not appear in large numbers at all. Nectarine growers typically apply up to 5 insecticide sprays to control thrips during the damage sensitive period, but under an Integrated Fruit Production (IFP) system, it will be important to reduce this number. Prediction of the time when thrips influx is most likely to occur, or alternatively, identification of when risk of thrips damage is low, would allow nectarine growers to more efficiently target their insecticide sprays and reduce the total number of applications.

NZFT is occasionally found in the seed heads of Verbascum thapsus L., during winter in Central Otago, but the numbers that survive the winter are too low to account for the numbers that suddenly appear on summer fruit crops in spring. They do, however, overwinter in large numbers in Canterbury, particularly on gorse (Ulex europaeus L.), and it has been hypothesised (G.F. McLaren, pers. comm.) that they could be carried on air currents from Canterbury to Central Otago. Surveys of thrips aerial activity using sticky traps (McLaren 1984) noted that thrips activity increased on warm days $\left(>17^{\circ} \mathrm{C}\right)$ with hazy cloud cover. These conditions are associated with an easterly wind flowing onto Canterbury, and the wind trajectories described in such conditions (S. Reid, National Institute for Water and Atmospheric Research) move in a south-westerly direction from Canterbury to Central Otago and could be a source of thrips. Winds over Christchurch that could carry thrips to Central Otago could range from northerly to easterly $\left(0-90^{\circ}\right)$.

In this paper, we investigate whether thrips influxes, during a season (as detected by sticky traps) can be predicted by environmental variables in Canterbury and Otago such as temperature, wind speed and wind direction, and we develop a simple model to predict when the risk of thrips influxes is high. Aerial trapping of NZFT in 
Canterbury was also carried out to further investigate the theory of thrips movement from Canterbury.

\section{Trapping}

Thrips were trapped at Clyde Research Centre between 1994 and 1998 using white sticky boards $250 \mathrm{~mm}$ by $200 \mathrm{~mm}$, painted with white Dulux Super Enamel with low ultra violet reflectance (Teulon and Penman 1982). The boards were enclosed in plastic bags and coated on one side with a polybutene adhesive. Sixteen traps were installed in a square with 4 traps facing each direction and suspended $1.5 \mathrm{~m}$ above the ground on the wire fence surrounding the meteorological equipment. The traps were in an exposed position, outside the orchard and $50 \mathrm{~m}$ from the nearest fruit trees. Traps were cleared daily between $10 \mathrm{a} . \mathrm{m}$. and $11 \mathrm{a} . \mathrm{m}$. (peak flights occur between $11 \mathrm{a} . \mathrm{m}$. and 4 p.m.), hence each day's total relates to thrips arriving on the boards in the preceding 24 hours. Trapping continued daily from pink to shuck fall.

\section{Model development}

Using data on the mean daily thrips catch (from a total of 16 sticky traps) during 1994, 1995 and 1996, we investigated whether daily thrips catches were related to local temperature in Clyde, average wind speed in Clyde and wind direction in Canterbury. Various measures of the previous day's temperature in Clyde were used as regressors, including mean temperature, maximum temperature, degree-hour total between 11a.m. and 4 p.m. (when peak flights occur), and degree-hour totals in 24 hours above base temperatures of $0,13,14,15,16,17,18,19$ and $20^{\circ} \mathrm{C}$. Average wind speed in Clyde was calculated as the mean of 4 records in the 24 hours prior to trap clearance. Mean wind direction (expressed in degrees) in Christchurch, Canterbury, was determined for different time periods using data supplied by Metservice, Christchurch, with information collected at Christchurch airport. It was estimated that a parcel of air would take approximately 24 hours to reach Clyde from Canterbury (S. Reid pers. comm.). Consistent with this theory, thrips arriving in Clyde on any particular day would have left Canterbury approximately 24 hours earlier, and their arrival would not be detected in the traps until a day later. Hence we investigated the relationship between trap catch and the mean of the 8 wind direction records during the previous 48 hours, the mean of 4 wind direction records during the previous 24 hours and during the 24 -hour period one day earlier. These environmental parameters were investigated firstly as single variates in a linear regression analysis, and then, stepwise multiple regressions were carried out. In a stepwise regression, the effect which most improves the $\mathrm{R}^{2}$ value is added first and new regressors are only added to the model if they improve the fit.

The dependent variable in the regressions was the mean daily thrips catch per trap from the beginning of September until the 15th October, giving between 38 and 44 data points. Thrips catches in the sticky traps always show a marked increase around mid October, which is when the second generation of adults emerges, derived from eggs laid in nectarine flowers in early September. The present analysis was restricted to the first generation of adults.

\section{Suction trapping of thrips in Canterbury}

To further investigate the hypothesis of thrips movement from Canterbury to Otago, thrips were monitored in a suction trap operating at Lincoln. The suction trap designed on a Johnson and Taylor principle (Johnson and Taylor 1955) collected thrips from $7.5 \mathrm{~m}$ above ground by a $30 \mathrm{~cm}$ aerofoil fan that sampled $1 \mathrm{~m}^{3}$ air per second and delivered it into an enclosed cone. The trap was cleared of thrips daily from September 1 to November 1 in 1997 and 1998. We investigated whether these catches were related to local temperature and whether trap catches in Otago were related to catches in Canterbury in the preceding days.

\section{RESULTS}

The numbers of thrips caught by the sticky traps varied between the three seasons (maximum daily catch 5 thrips/ trap in 1994, but only 0.5 and 0.9 thrips/trap in 1995 and 1996 respectively) but similar environmental conditions within each season were 
the best predictors of trap catch in single variate models. Local (Clyde) wind speed did not affect trap catch in any season $(\mathrm{P}>0.05)$. Of the different measures of wind direction, the mean direction of 8 records, 48 hours prior to trap clearance was the best predictor of thrips catch in $1994\left(\mathrm{P}<0.0001, \mathrm{R}^{2}=0.38\right)$ and $1995\left(\mathrm{P}=0.029, \mathrm{R}^{2}=0.108\right)$. Daily thrips catches were highest for low numerical values of wind direction in Christchurch, which is consistent with the theory of thrips being carried on air currents from Canterbury to Otago. Thrips catches increased as the previous day's temperature in Clyde increased. Of the different measures of temperature in Clyde, degree hours (above $12^{\circ} \mathrm{C}$ ) gave the best fit in $1994\left(\mathrm{P}<0.0001, \mathrm{R}^{2}=0.356\right)$, maximum temperature gave the best fit in $1995\left(\mathrm{P}=0.0013, \mathrm{R}^{2}=0.24\right)$ and degree hours (above $0{ }^{\circ} \mathrm{C}$ ) gave the best fit in $1996\left(\mathrm{P}=0.036, \mathrm{R}^{2}=0.11\right)$.

The best two-variate models for each season from the stepwise regressions included wind direction in Christchurch and some measure of temperature in Clyde, but the low trap catches and $\mathrm{R}^{2}$ values in $1995\left(\mathrm{R}^{2}=0.28\right)$ and $1996\left(\mathrm{R}^{2}=0.19\right)$ meant that a useful predictive model could not be developed. Instead, the 1994 data were explored in order to make a quantitative assessment of the risk of thrips influx and the model derived was then tested against 1995 and 1996 data. The best model for the 1994 season using the variates wind direction and degree-hours above a threshold of $12^{\circ}$ $\mathrm{C}$, had an $\mathrm{R}^{2}$ value of 0.51 . Maximum daily temperature is a simpler and more meaningful measure of temperature for growers and the $\mathrm{R}^{2}$ value of 0.46 for the model using maximum temperature and Christchurch wind direction was only slightly lower. The two parameter model used was:

TRAP CATCH=1.85-0.012WIND+0.136CMAXT

where: WIND $=$ mean of 8 wind direction records in the 48 hours prior to trap emptying (coefficient s.e. $=0.004, \mathrm{P}=.0078$ ), $\mathrm{CMAXT}=$ maximum temperature in Clyde on the day prior to trap clearance (coefficient s.e. $=0.06, \mathrm{P}=0.03$ ).

This two-variate model was used to predict whether the risk of thrips arriving would be high or low, based on an arbitrary definition of catches greater than 2 representing high risk and catches less than 2 representing low risk (Fig.1). The line separating high and low risk was derived from the above equation by substituting TRAP CATCH $=2$, thus giving high risk when

\section{CMAXT $>1.1+0.088$ WIND}

\section{Clyde Research Orchard, 1994}

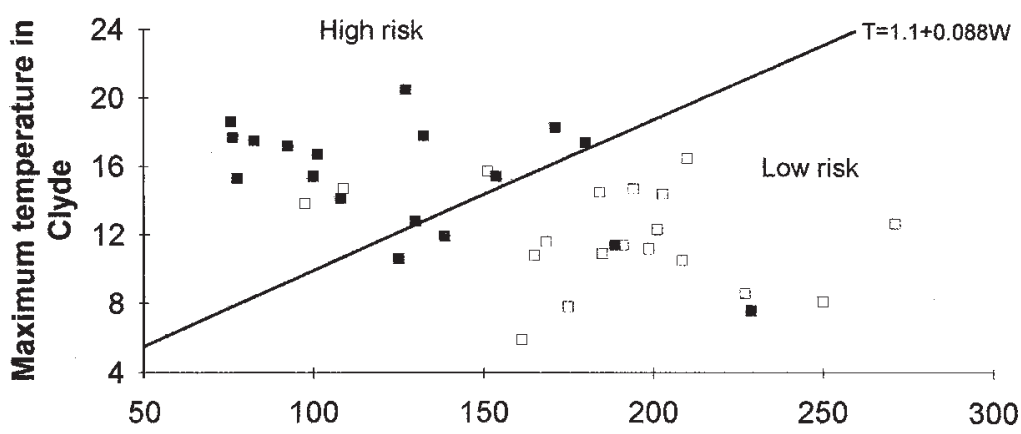

\section{Average wind direction in Christchurch for previous 48 hours}

FIGURE 1: Evaluation of areas of high and low risk of thrips influx from a twovariate model derived from 1994 data and compared with field data for daily thrips catches of less than 2 per trap ( $\square$ ) and greater than 2 per trap $(\square)$. The line is [Temp] $=1.1+0.088$ [wind direction] (see text). 


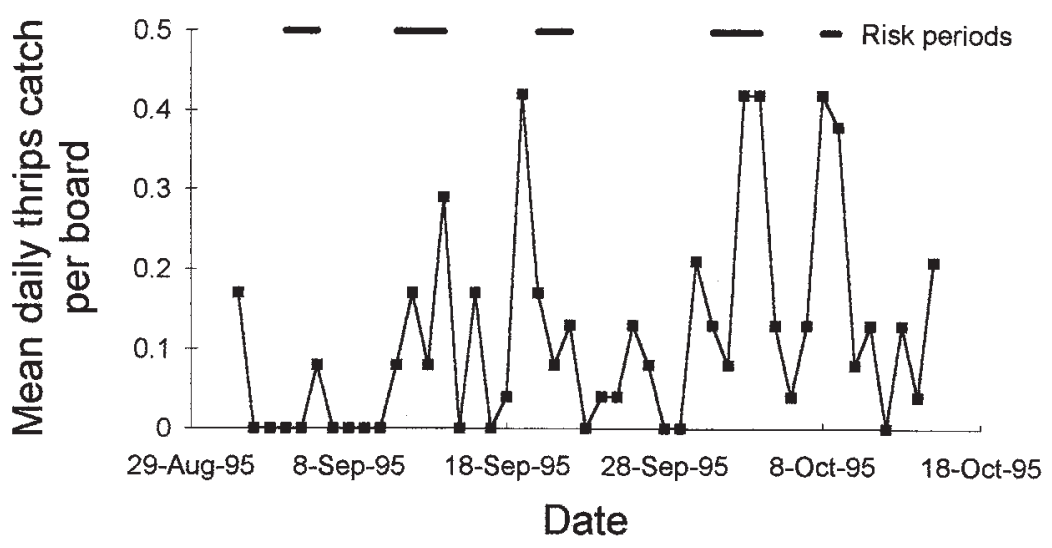

FIGURE 2: Risk periods predicted from the 1994 model compared with daily thrips catch in 1995.

This model described the 1994 data very well, with only a few exceptions (see Fig. 1). The two thrips catches greater than 2 per trap, obtained despite predicted risk being low, both followed high catches on the previous days and may be explained by the time taken for thrips to settle after a flight. The 1994 model was also successful at predicting four risk periods for 1995 (Fig. 2) but less successful for 1996 (Fig. 3) when only three out of six predicted risk periods actually had high thrips catches.

\section{Suction trapping in Canterbury}

There was a significant relationship between NZFT caught by the suction trap at Lincoln and the previous days temperature (the day on which thrips were actually caught) in both $1997(\mathrm{P}=0.028)$ and $1998(\mathrm{P}=0.0003)$. Moreover, the major thrips flights during spring 1997 and 1998 were always associated with a maximum temperature greater than $20^{\circ} \mathrm{C}$ in Lincoln. There were four major flights in Lincoln between 1/9/97 and 15/10/97, and two of them were followed by increased thrips catches on the boards in Otago. In 1998, 3 out of 4 flights in Lincoln were followed two to three days later by high trap catches in Clyde.

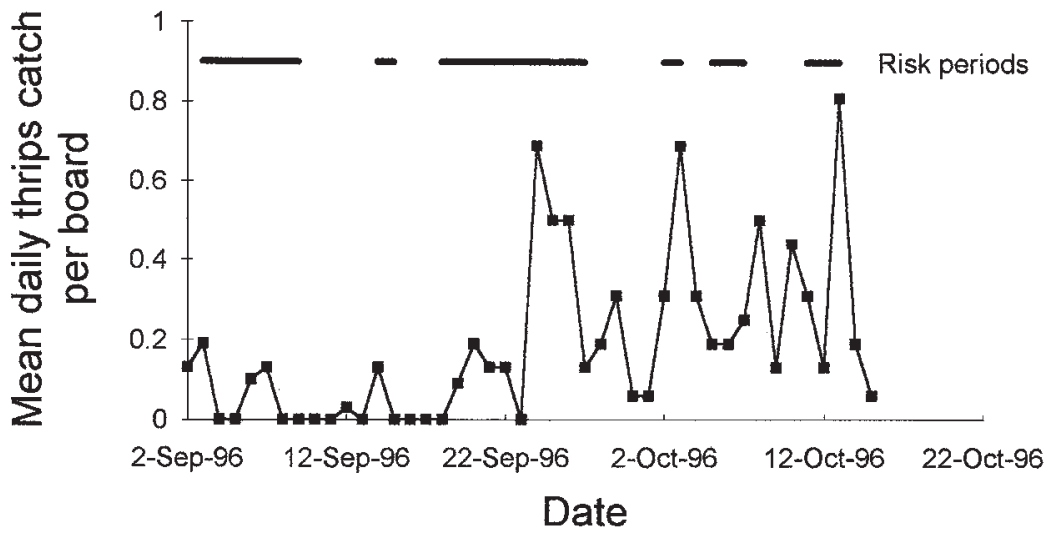

FIGURE 3: Risk periods predicted from the 1994 model compared with daily thrips catch in 1996. 


\section{DISCUSSION}

Of the parameters tested, the best predictors of thrips arrival in traps in Central Otago were the wind direction in Christchurch and some measure of temperature in Clyde. Thrips are highly mobile, and the numbers intercepted by the traps may also be affected by rain, wind, cloud cover, humidity and orchard activities such as local mowing or spraying. The analysis is further complicated by the fact that when thrips arrive, they do so over a number of days and can then take several days to settle on a new host.

Suction trapping of thrips in Canterbury supports the theory of thrips movement from Canterbury to Clyde, since thrips influxes occurred two to three days after major flights of thrips in Canterbury. However, since this delay is greater than the 24 hours estimated for parcels of air to travel to Clyde, presumably because of the time taken for thrips to settle, it would be useful to investigate as a regressor, wind direction in Canterbury earlier than 48 hours prior to trap catch.

The preliminary model based on 1994 data performed reasonably well, but sticky traps were not very efficient in 1995 and 1996 and caught low numbers of thrips compared to the suction trap operating at Lincoln. A standard suction trap such as that used previously at Clyde (McLaren 1995) would more accurately reflect aerial activity in Central Otago and could provide more rigorous test data. It is hoped that the model may be improved either by first predicting flights in Canterbury (on the basis of temperature) or by utilising wind direction further back than 48 hours. It is not envisaged that a model would be used alone as a basis for recommending thrips control measures, but when risk periods were predicted, growers would be advised to sample from their own trees and make a decision on the need to spray based on spray thresholds. By automating part of this process, the labour intensive daily monitoring of thrips by advisers may be avoided.

\section{ACKNOWLEDGEMENTS}

We thank Dave Teulon for providing suction trap data from Lincoln and Nigel Barlow for constructive comments on the manuscript. This work was funded by the NZ Foundation for Research Science and Technology contract number CO6615.

\section{REFERENCES}

Johnson, C.G and Taylor L.R., 1955. The development of large suction traps for airborne insects. Annals Appl. Biol. 43: 51-61.

McLaren, G.F., 1984. Annual Report Entomology Division, Department of Scientific and Industrial Research 1983-84.

McLaren G.F., 1992. Thrips on nectarines in the spring. Proc. 45th N.Z. Plant Prot. Conf.: 111-115.

McLaren, G.F., 1995. Factors influencing the monitoring of New Zealand flower thrips Thrips obscuratus (Crawford). Proc. Australia and New Zealand Thrips Workshop: Methods, Biology, Ecology and Management, 25-27 July 1995, Gosford, Australia: 52-62.

Teulon, D.A.J. and Penman D.R., 1982. Colour preferences of New Zealand Flower thrips (Terebrantia:Thysanoptera). N.Z. Entomologist 15: 8-13. 